\title{
A construção de uma história do cinema brasileiro: política estatal e cinema alternativo nos anos Embrafilme \\ Roberto Moura*
}

\section{RESUMO}

Como os historiadores profissionais nāo se interessaram pelo fenômeno, foram intelectuais ligados às esquerdas que produziram efetivamente nos anos 50 os primeiros textos que fundam uma história do cinema brasileiro. Com o subsequente protagonismo do Estado brasileiro na cultura e no cinema nacionais sob os governos militares nos anos 70 , configurou-se um excessivo centralismo na atenção dessa história em relação a um setor que surge paralelamente a sua própria elaboração. Trata-se do Cinema Novo que, paradoxalmente, se tornaria hegemônico na poderosa Embrafilme, exigindo-se que essa história da modernidade do cinema brasileiro seja complementada e sejam discutidas algumas de suas avaliaçōes, hoje consensualmente aceitas, que configuram aspectos cruciais do cinema brasileiro contemporâneo.

\section{ABSTRACT}

As professional historians did not pay much attention to this universe, there were leftist intelectuals who wrote in the 50's the first lexts which founded a history of Brazilian cinema. With the subseguent center role played by the State in national cullure and in our cinema in the ro's under the militan' governements, it was established an excessive allention of this histon towards a setor which appears at the same time when those reserchs were produced, Brazilian's Cinema Novo, which, paradoxically, turn to be hegemonical in the powerfull state institution directed to the activity, what creates a need that this histony of modern Brazilian cinema shoud be complemented, and be discussed some of its central evaluations today consensually accepted, crucials in the management of contemporan' Brazilian cinema.

\footnotetext{
* Roberto Moura é professor do Programa de Pós-Graduação de Comunicação da UFf e autor de obras sobre a indústria do espetáculo no Brasil.
} 
"O fato de um passado recente do cinema brasileiro ser objeto de retrospectivas e debates no Brasil e no exterior, ultrapassa o interesse puramente histórico ou acadêmico, sendo mais a reativação de um capital que pode ter o seu papel no jogo político em que decide a viabilização de seu futuro."

(Ismail Xavier, "O Cinema Brasileiro Moderno")

A preocupação e a tarefa de elaborar uma história do cinema brasileiro, entendida como tendo seu objeto no fenômeno da produção de filmes no país, surge no pós guerra, momento da generalização/democratização de uma outra visão do fenômeno cinematográfico e de suas possibilidades contraposta à dominante vinculada ao cinema de entretenimento de Roliude mas de forte fatura ideológica. Fruto do trabalho de jornalistas, realizadores cinematográficos e cinéfilos nos anos 50 , e, nos anos seguintes, de críticos e especialistas dos departamentos de cinema e vídeo das universidades nacionais, já que a comunidade dos historiadores profissionais brasileiros ainda não se vinculou substantivamente a esse projeto nem deu a ele qualquer apoio epistemológico ou institucional - no entanto configurou-se o que podemos compreender como uma "história do cinema brasileiro" relatada numa bibliografia importante e bastante sofisticada academicamente, cujas linhas gerais se tornaram culturalmente reconhecidas do país, como foram absorvidas pelo imaginário midiático ${ }^{1}$ 70 nacional:

O que peculiariza essa história- numa observação desse ponto de vista de início de milênio que olha para meio século de ocorrências - é que ela, mesmo percebendo a extensão do fenômeno cinematográfico no Brasil, inaugurado em filmagens em águas e terras brasileiras ainda no final do século XIX, tem como seu tema central acontecimentos contemporâneos a sua própria constituição: o surgimento de um cinema moderno brasileiro em movimentos político-culturais e a sequiência da atuação desses realizadores nas últimas décadas. Assim, personagens, filmes e questões surgidas nesse passado recente rivalizam com vantagem na crescente bibliografia apontada para o cinema brasileiro com temas também, mas muito menos, prestigiados como a chanchada, "Limite", a "bela época" e mesmo aspectos do cinema brasileiro contemporâneo.

Em termos internacionais, uma vez que são progressivamente controlados seus circuitos de exibição pelos distribuidores norteamericanas a partir do final da primeira guerra mundial, com a crescente proeminência econômica, política, militar e cultural dos Estados Unidos no planeta, sabemos que o cinema receberia como contrapartida um desapreço da intelectualidade e do meio acadêmico, ambiente ainda liderado por escolas e pensadores europeus, como um tema culturalmente e 
historicamente irrelevante. Como que analogamente ao "ilusionismo" do cinema "clássico" produzido pelos estúdios daquele subúrbio de Los Angeles, que oculta seu aspecto discursivo e ideológico parra melhor atingir seu espectador, parece que não interessava que se desse profundidade à atenção sobre o cinema corrente além de sua extrema mas volátil notoriedade midiática.

Na Europa. na França, uma história do cinema começa como uma história de cinéfilos apaixonados que sem se preocupar com a consulta sistemática às cópias e a documentos se contentavam em confiar em suas memórias. Mesmo se autores como Jean Mitry reivindicam o status de "história" para suas pesquisas pioneiras - "eu quis extrair uma certa filosofia dos acontecimentos, das obras, dos fatos, procurando situar a evolução artística, industrial e econômica do filme no seu contexto social universal e de justificar suas estruturas justificando sua infra-estrutura. Em suma. me esforcei em fazer história no sentido exato da palavra" - apesar disso há relativamente pouco tempo atrás. em 1989, Jean-Pierre Jeancolas fazia uma avaliação bastante depressiva sobre os estudos históricos do cinema francês. Afirmou o autor que as monografias que se multiplicavam, algumas de excelente qualidade. não ultrapassavam à condição de uma acumulação heterogênea de esforços. se limitando a ser um "vassto panorama impressionista com pontos de luz e zonas de sombra, do qual não se estrutura nenhuma linha de força".

O pionerismo de George Sadoul que produziria uma história do cinema francês narrativa, cronológica. teleológica que se tornaria modelar uma vez compreendido o cinema nacional como objeto natural de uma história do cinema; e o trabalho recente de historiadores como Michèle Lagny. questionando e sistematizando suas ferramentas e estabelecendo parâmetros teórico-metodológicos estáveis para a pesquisa, garantem à França um papel exponencial nesse campo e já hoje um nítido reconhecimento institucional interno. No entanto, a dificuldade do seu reconhecimento no exigente e pluripolarizado universo acadêmico e cultural francês em nada se assemelha ao que contemporaneamente acontecia no Brasil quando se elabora uma história da aventura cinematográfica brasileira.

Aqui, se os historiadores profissionais não se interessaram pelo cinema brasileiro, e sem se tirar o mérito de críticos e cinéfilos paulistas que primeiro se encantaram nos anos 50 com cópias até então esquecidas dos primórdios da produção brasileira - foram intelectuais ligados às esquerdas. como o jornalista e depois cineasta Alex Vianny, o militante e crítico Paulo Emílio de Salles Gomes. e o jovem Glauber Rocha que produziram efetivamente os primeiros textos que fundam uma história do cinema brasileiro. 
Alex Viany publica modestamente em 59 uma "Introdução ao Cinema Brasileiro" 4 , onde procura resgatar e organizar as informações que retirou de sua vivência como jornalista e realizador cinematográfico, uma vez que não haviam arquivos nem acervos acessíveis, chegando no seu capítulo final a um diagnóstico do universo cinematográfico brasileiro contemporâneo. Para Viany é imediata a percepção que a pesquisa histórica se propõe no presente e que o conhecimento que produz deve imediatamente interferir no curso do universo que aborda, uma teleologia implícita que se refere tanto a Sadoul como aquele momento da jovem cultura política dos anos 50 , a quem ele como Paulo Emílio se aliariam como irmãos mais velhos. Se o universo do cinema comercial de entretenimento no país se enredava em sua crise crônica asfixiado pelo pequeno nicho no mercado exibidor deixado pelo distribuidor norte-americano - no Rio os anos 50 vão assistir o fechamento e a decadência das produtoras de chanchada, enquanto em São Paulo a continuidade das novas produtoras depois do fechamento da Vera Cruz só era mantida por uma política compensatória de prêmios e financiamentos mantida pela prefeitura -, surgia a reboque da movimentação de congressos cinematográficos uma nova geração diretamente ligada à universidade propondo um cinema como forma de expressão artística e como ferramenta de conscientização do país para a tarefa revolucionária de inclusão das enormes massas rurais e urbanas frente a falácia da democracia nacional instituída como estrutura de poder e de interesses econômicos estrangeiros.

A ascensão das esquerdas em termos internacionais, que seria internamente sublinhada pela ascensão de João Goulart ao poder, se não dialogaria diretamente com a eclosão do Cinema Novo, definiria um contexto favorável à obtenção de recursos financeiros para a realização dos filmes iniciais do movimento, a que se somaria as relações privilegiadas de alguns de seus fundadores com personagens cruciais do mundo cultural e financeiro do país. Um movimento sem carterinha nem bases estáveis de produção cinematográfica deflagrado por Glauber Rocha, que depois de uma peregrinação nacional, se fixa no Rio, definindo uma relação de colaboração e cumplicidade, anárquica e fraterna, com uma dissidência do "O Metropolitano" jornal do Centro Popular de Cultura, órgão privilegiado do movimento estudantil.

O reconhecimento desses primeiros filme nos festivais internacionais, trazendo o aval tão ansiado pelo universo cultural pátrio para obras e artistas nacionais, acatado até pelos setores mais conservadores, o momento extraordinário de renovação e politização das artes e dos produtos de entretenimento por que passávamos, o surgimento dos cadernos de cultura nos jornais diários e de uma nova geração inspirada de críticoscinematográficos interlocutores imediatos do Cinema Novo, além da extraordinária atuação de Glauber como realizador, ideólogo, líder e ícone do 
artista revolucionário, contribuiriam para a repercussão que teria seu livro lançado em 63, em continuidade à proposta de Alex Viany, dando nova dimensão ao fenômeno de produção de filmes no país. Se Alex fizera apenas uma "introdução", Glauber chega com uma "Revisão crítica do cinema brasileiro" em que partindo de Humberto Mauro e, mais relutantemente, de Mário Peixoto, como terreno fértil para se assentar uma tradição, se volta para o ambiente do cinema brasileiro contemporâneo. avaliando criticamente a experiência fracassada do cinema industrial da Vera Cruz e propondo tanto uma nova ética e uma nova estética para o "autor" cinematográfico, como a correção de rumo das propostas de expansão da ação do Estado frente à atividade cinematográfica no pais - em fase de discussão em comissões dos ministérios da cultura e da indústria e comércio - na defesa do filme brasileiro no mercado dominado pelo imperialismo cinematográfico norteamericano.

O golpe militar de 64 ocasionaria uma importante "inflexão por ruptura" do processo cultural brasileiro, interrompendo sua enorme vitalidade conjuntural através das armas da repressão policial pura e simples e da censura das obras. No entanto, naqueles anos que endurecem com a promulgação do Ato Institucional $n^{\circ} 5 \mathrm{em} 68$, a força jovem e democratizante do momento anterior produzia o importantíssimo fenômeno da construção de uma "cultura de oposição" no país, com a qual identificavam-se importantes segmentos da sociedade. hegemônica nos cadernos de cultura dos jornais e na nascente "imprensa nanica" associada à manutenção de uma produção artística onde os conteúdos de esquerda dialetizavam com visões contraculturais na sua avaliação do novo momento, e onde se mantinha como pedra angular o Cinema Novo, com seus filmes que imediatamente tematizam o golpe e fechamento político, o episódico fim das utopias sob o governo militar.

Se o Estado brasileiro só tinha uma instituição voltada para um aspecto menor da atividade cinematográfica, o Instituto do Cinema Educativo - INCE e durante o desenvolvimentismo não passara de intervenções apenas especulativas, já em 66 o INCE perde uma letra e ganha amplitude, prenunciando a continuidade do interesse do Estado brasileiro sob novas mãos na atividade, interesse que seria confirmado com a fundação da Embrafilme em 69, inicialmente voltada a um hipotético e improvável comércio internacional para os filmes brasileiros, ambas as instituições tendo preenchidos seus quadros com profissionais do cinema egressos das produtoras paulistas pós-Vera Cruz e de outros ambientes politicamente conservadores do cinema brasileiro, enquanto o Cinema Novo se defendia e atacava com seus filmes e nos jornais.

Se o Cinema Novo fora subalternizado pela nova política estatal recebendo um quinhão menor na política de premiações e financiamentos 
referenciada por São Paulo desenvolvida pelo INC, os remanescentes do movimento original e uma nova dentição de cinema-novistas de segunda hora pela primeira vez começam a desenvolver verdadeiramente uma estrutura coletiva de produção e distribuição nacional de filmes: o importantíssimo episódio da Difilm, tão pouco abordado pela historiografia. Muita coisa acontece nesse país só na hora da crise, como numa nova disciplina agora absolutamente necessária a Difilm e as produtoras a ela associadas representam um sistema de produção e difusão de filmes coerente que percebe e potencializa seu prestígio nacional e internacional através de uma intervenção clarividente e laboriosa no mercado frente ao sistema hegemônico do cinema norte-americano no Brasil. Assim, procurase; operacionalizar as relações de produção antes vividas anarquicamente socializando os meios de produção e a renda dos filmes entre os realizadores; encarar de frente a questão da distribuição buscando aliados e jogando no circuito secundário e nos "cinemas de arte"; renovar as relações sociais de produção dentro das equipes, apostando numa contaminação da idéia dos "cinemas novos" para as novas gerações como uma tradição constituída de expressão e de luta. Isso enquanto os realizadores sofrem uma sistemática marcação da censura, tendo filmes sistematicamente cortados e proibidos, e mesmo uma campanha orquestrada na imprensa que fala da "linguagem maldita do Cinema Novo", o que provocaria resultados econômica e existencialmente desastrosos.

74 Nessa cultura de resistência certamente um dos protagonistas junto com Glauber foi Paulo Emílio, que juntamente com seus pares da geração Clima chegavam à maturidade intelectual e ao reconhecimento cultural e acadêmico. Paulo, que trabalha na criação de um primeiro departamento universitário voltado para o cinema na Universidade de Brasília, projeto abortado pelo golpe de 64, e depois do Departamento de Cinema da Universidade de São Paulo, se torna numa referência nesse universo cinematográfico em mutação e nesses anos desenvolve sua melhor produção, publicando sistematicamente textos críticos e do que poderíamos chamar de "estudos do cinema brasileiro" no Suplemento Literário do jornal Estado de São Paulo. Em 74 publica não apenas seu interessantíssimo livro sobre a primeira fase de Humberto Mauro em Cataguases, como seu ensaio "Cinema: trajetória do subdesenvolvimento" reconhecendo a densidade mas também a marginalidade da experiência nacional de produção cinematográfica e seus momentos exponenciais de representação e interlocução com a sociedade, chegando sua avaliação ao impasse contemporâneo que vivia o importante setor da classe formada pelo Cinema Novo.

É contemporaneamente ao texto de Paulo Emílio e de sua enorme repercussão no meio cinematográfico que se configuraria uma reordenação 
da política governamental quanto à cultura, já prenunciado pelo surgimento da Embrafilme em 69, que engoliria o INC se integrando no projeto mais amplo explicitado na Política Nacional de Cultura, como uma mudança da atitude governamental até então vigilante e punitiva quanto ao "quisto rebelde da produção simbólica nacional". A gestão Jarbas Passarinho no Ministério da Cultura vai se constituir num momento de virada quanto ao meio cinematográfico. É quando o ministro passa a se apropriar de posições nacionalistas, agora restritas ao plano cultural preocupado em criar uma identidade nacional ao nível do simbólico, enquanto o Estado dava continuidade a sua política de internacionalização da economia brasileira e de desenvolvimento excludente.

A ação sistemática da repressão e da censura e as ofertas de recursos e poder na Embrafilme virtualmente terminam o movimento do Cinema Novo, na metade dos anos 70 , ocasionando uma mudança de rumo para seus antigos integrantes. Suas antigas propostas do tempo de Goulart buscando a cumplicidade do Estado socialista e da burguesia progressista nacional são atendidas por Geisel e Passarinho, quando o Estado perdera qualquer legitimidade política e a burguesia pragmaticamente se aliara às empresas multinacionais que começavam a delinear uma grande virada globalizante depois da emergência internacional das esquerdas e do Terceiro Mundo que assistira o pós-guerra. As antigas e novas liderança entre os excinemanovistas com sua visão pragmática do contexto declaram que a Passarinho caberia a "glória de implantar uma indústria cinematográfica brasileira", a firmando a autonomia dos realizadores cinematográficos e a democratização dos recursos, enquanto efetivamente se adensa o controle estatal e se implanta a hegemonia de uma elite. Se o prestígio do grupo já the garantia uma hegemonia midiática nos cadernos de cultura como na crítica, o poder na Embrafilme faz que ele passe a falar em nome de toda a classe cinematográfica, o combate ao imperialismo cinematográfico justificando tudo, embora no novo momento a Difilm - base de uma cultura de oposição no país - tivesse se tornado obsoleta. A luta seguiria no seio do próprio estado autoritário, liderados por gênios da raça, entre eles militares e cineastas.

Juntamente com elementos egressos do campo da publicidade e do meio financeiro, artistas e intelectuais formados pelas esquerdas no momento anterior se tornam personagens cruciais para o funcionamento do Plano Nacional de Cultura, que através da criação de grandes instituições tornaria o Estado o virtual protagonista da cultura e do cinema nacional nas próximas décadas. A Rede Globo, garantida por um decreto-lei a legitimidade do investimento do grupo Time-Life proibida pela Constituição, como uma instituição para-estatal comporia a nova cena como um poderoso sistema multimidiático em expansão e absorveria muitos artistas e 
intelectuais atraídos por suas possibilidades superlativas. Para muitos, momentaneamente desprivilegiados pela situação política do país, era tempo de pragmatizar.

Comentários críticos mais ou menos pertinentes vindos de diversos lados e a partir de diversos pontos de vistas, são unanimemente descartados na campanha de Diegues contra as "patrulhas ideológicas" e nos textos enfáticos de Glauber? ${ }^{7}$ A perspectiva muito mais ampla e sofisticada dos novos dirigentes se comparada às limitações dos anteriores, faria com que a Embrafilme se tornasse não apenas a mais poderosa produtora e distribuidora do país, como uma instituição cultural que se volta para o cinema brasileiro de forma complexa, preocupada e gastando parte significativa de sua dotação com a preservação dos filmes, com a pesquisa e com sua história, publicando importantes trabalhos em parceria com editoras e universidades, editando a revista mais importante do período (a FilmCultura), promovendo eventos e festivais.

É nesse momento, com a estruturação dos primeiros departamentos universitários pelo país voltados para o cinema e com o amadurecimento de uma geração de críticos que viera dos movimentos culturais e da cultura de resistência e com o Departamento Cultural da Embrafilme - que efetivamente se configura uma história do cinema brasileiro como um desenvolvimento e um amadurecimento do trabalho dos pioneiros. Uma vez que devido à carência de fontes, pouco se pode acrescentar quanto aos

76 filmes, realizadores e ciclos dos primeiros tempos, seu foco principal seriam os anos anteriores, os acontecimentos, os realizadores e os filmes em torno do surgimento do Cinema Novo e seu enfrentamento com o Cinema Marginal nas circunstâncias de uma cultura e um cinema de oposiçãoÉ muito importante a relação entre essa geração de críticos principalmente do eixo Rio - São Paulo - Belo Horizonte, cujo trabalho se constituiu mesmo numa proto história por sua qualidade e esse universo universitário em transformação - caminho do próprio Paulo Emílio - para o patamar que atinge um pensamento cinematográfico brasileiro em sua dialética essencial com aqueles "anos de ouro", a universidade se tornando um espaço recorrente de atuação de artistas e intelectuais em permanente conflito com o instituído e com o hegemônico durante aqueles " anos de chumbo". Assim, se de São Paulo, próximos de Paulo, vêm os livros cruciais de JeanClaude Bernadet, Ismail Xavier, e Maria Rita Galvão, no Rio, junto com Alex, aparecem os de José Carlos Avellar, Ronald Monteiro e José Carlos Monteiro, entre muitos outros, que se tornariam uma referência para novas gerações que ingressam nas novas pós-graduações e instituições de pesquisa e preservação que se abrem concomitantemente no país.

$O$ processo de democratização representa uma nova inflexão da sociedade brasileira, a volta à democracia eleitoral. Essa segunda transição 
da modernidade recente nacional que ocorre nos anos 80 é gradual em direção à superação dos governos militares e de sua conjuntura cultural. Ao contrário de 64 em que a transição se dá abruptamente e por ruptura esta se daria paradoxalmente em sintonia com o que fora plantado sob os governos militares, enquanto vão sendo progressivamente exorcizados do ambiente cultural do país os ecos do momento anterior, aquela estranha afinidade que se propunha entre a arte engajada e a cultura do alto modernismo. Para esse rumo dos acontecimentos evidentemente iria favorecer e refletir os acontecimentos no Leste europeu e a vitória do neoliberalismo no plano internacional.

Assim, a reafirmação da ordem mundial tomada episodicamente indiscutivel pelo poder militar norte-americano, assentida com maior ou menor relutância e oportunismo por seus outros aliados europeus do primeiro time - resultaria numa globalização sem precedentes do imperialismo econômico. provocando o surgimento de novas concep̧̧ões e posturas filosóficas, políticas, existenciais e artísticas que caracterizariam uma nova crise da razão que teria como um dos seus sintomas a contestação das vanguardas e dos modernismos nacionalistas.

A criação, em contraste com a década anterior, de um novo comportamento, novas mentalidades, no ambiente cultural, desideologizado, dessubstancializado diriam criticamente alguns. mas altamente pragmático e profissional, traria benefícios evidentes para o universo do cinema nacional em termos de estrutura administrativa, capacitação técnica, renovaçĩo tecnológica e empresarial, como repercutiria positivamente no financiamento da pesquisa e da preservação. Com a chegada de Collor ao poder nos anos 90 de uma penada são varridas as instituições voltadas para o cinema brasileiro e a legislação de reserva de mercado, iniciando-se o último capítulo do cinema brasileiro financiado por uma legislação que estabelece o mecenato, na verdade um falso mecenato pois é efetivamente uma renúncia fiscal do Estado, mas que transfere às estatais e multinacionais a decisão sobre uma crescente produção nacional.

Tendo participado de dois livros que pelo seu caráter abrangente e totalizante são um resultado e uma coroação do desenvolvimento desses estudos sobre o cinema brasileiro que marcaram esse último quarto de século no Brasil, tanto da "História do Cinema Brasileiro"s publicado em 87 como da "Enciclopédia do Cinema Brasileiro", ambos organizados por Fernão Ramos, o último em parceria com Luiz Felipe Miranda - desenvolvi uma reflexão que me pareceu produtiva sobre essa história do cinema brasileiro. Percebendo sua parcialidade, me preocupava o caráter metonímico que tomava, induzindo o leitor a compreender a parte como o todo. Percebi que, compreensivelmente em face do desaparecimento dos filmes da primeira metade do século por descaso. descuido ou incêndio, se 
para trás ficaram "cinemas invisíveis", filmes, ciclos e surtos cinematográficos invisíveis para a história, que a pesquisa tem que localizar a partir de outros documentos, que haviam "cinemas invisíveis" também na história do cinema moderno, fatos fílmicos e cinematográficos posieriores ao surgimento dessa historiografia nos anos 50 , posteriores mesmo a minha entrada nesse universo na virada dos anos 70 .

Especulo que isso ocorreu como contrapartida da excessiva centralização do poder no fenômeno Embrafilme com suas múltiplas e eventualmente contraditórias repercussões no universo cultural e cinematográfico brasileiro, definindo linhas de foco e pensamento excessivamente hegemônicas - o que justificaria uma atividade de complementação em relação à história já produzida que, que trazendo novos elementos, inserindo na histórias outros filmes, permitissem outras compreensões do passado recente do cinema brasileiro. Me parece particularmente importante o tema do protagonismo estatal na cultura e no cinema brasileiro, a repressão associada à cooptação abalando a cultura de resistência que se montara depois do golpe militar em 64 , como elemento significativo para compreender os filmes e o universo cinematográfico que se redefine a partir de 74 do qual o universo cinematográfico contemporâneo é um continuum, aspecto recalcado ou despotencializado nessa historiografia recente.

Uma complementação e revisão dessa "história do cinema brasileiro" me parece se impor tanto pela própria qualidade e status cultural a que atingimos, como pela importância do seu impacto no ambiente mais amplo do cinema brasileiro e da sociedade contemporânea, pois ela informa as cinematecas em sua tarefa de preservação dos filmes, informa o direcionamento dos novos trabalhos na Universidade, informa o sistema que dá a voz e o poder da classe frente ao Estado. Se considero importante que se corrija a excessiva concentração da atenção em determinados filmes e autores e mesmo que a pesquisa no Brasil realize projetos sobre largos corpus de filmes, é crucial num momento de crise como o que vivemos com a desmobilização da Cinemateca do Museu de Arte Moderna do Rio de Janeiro que as instituições encarregadas da preservação de filmes se preocupem com as matrizes de cinematografias menos conhecidas e mesmo tenham uma política ativa para sua localização.

Por outro lado, no ano passado quando a Presidência da República organizou o GEDIC - Grupo Executivo para o Desenvolvimento da Indústria Cinematográfica para reestruturar a participação e a regulamentação do Estado na atividade no país liderado pelo Ministro Chefe da Casa Civil e com um conselho consultivo composto por cinco membros, um representante das multinacionais, um representante da Rede Globo e três cineastas, é essa história que dá respaldo para todos os três nomeados 
sejam egressos do Cinema Novo. Pode-se louvar a durabilidade e a capacidade de renovação do grupo que partindo de um projeto revolucionário de esquerda, se ajusta nos anos 70 a um projeto de capitalismo estatal, nos 90 a outro como parceiros da globalização e das distribuidoras norte-americanas e agora estão prontos a continuar a liderar a classe durante o "lulismo". No entanto eles representam apenas os interesses de um importante setor da classe e o equívoco de que eles representam o cinema brasileiro com o assentimento da maioria como expressão de uma visão nacionalista tem sido, a meu ver. nociva.

Para as tarefas da incorporação de aspectos complementares do fenômeno cinematográfico brasileiro não descarto a participação dos historiadores nessa tarefa, dando a ela qualidade técnica e peso institucional e a publicação de "A História vai ao Cinema"" em 2001 organizado por Marizal de Carvalho Soares e Jorge Ferreira resultado do projeto História em Vídeo do Departamento de História da UFF - é um passo nessa direção. O projeto fez coincidir em textos analíticos os temas do trabalho de historiadores com filmes do cinema brasileiro moderno com "sucesso de público e de crítica". tomando-os como expressão de visões em movimento e de mentalidades sobre momentos e questōes da sociedade brasileira. Se o livro ainda não visa uma sistematização de propostas ou mesmo perceber peculiaridades históricas da produção cinematográfica nacional desse passado recente do cinema brasileiro, revelando uma distância dos historiadores desse território específico como da materialidade própria do discurso cinematográfico, nesse mesmo ano é publicado "O Cinema Brasileiro Moderno de Ismail Xavier ${ }^{10}$ que desenvolve uma proposta abrangente de representar esse passado recente e seu desdobramento no contex to do cinema brasileiro contemporâneo.Ismail se volta para o processo que envolveu o Cinema Novo e o Cinema Marginal, entre final da década de 1950 e meados dos anos $70^{\circ}$, que considera como "o período estética e intelectualmente mais denso do cinema brasileiro", o observando a partir dos movimentos dos cineastas nos dois pólos da polêmica. se estendendo numa observação introdutória ao cinema brasileiro contemporâneo. Se o primeiro artigo dos três que formam o livro se volta para as circunstâncias político-culturais do fenômeno, o segundo se volta para os filmes produzidos depois do golpe, se estendendo para outras vozes na intensão de ser mais panorâmico. o último se voltando para Glauber Rocha.

Se o livro dá solidez em seu partido incisivo e sintético a esta historiografia já clássica sobre o cinema brasileiro, pode ser tomado como um ponto de partida consistente para a tarefa de complementação e. posteriormente, discussão de seu diagnóstico. Cabe a uma visão complementar que parta das estruturas de produção cinematográfica no 
período, considerando a convivência de situações e projetos diversos do universo cinematográfico brasileiro. Pois, paralelamente ao cinema cultural produzido pela Embrafilme, haviam outros importantes produtores, setores identificados por uma proposta de um cinema erótico de entretenimento que mantinha relações secundárias com o Estado, atraídos por suas bilheterias mas chocado por seus excessos, e setores voltados para o importante mercado do curta-metragem que se abre no período. Se a perda do élan modernista em $85 \mathrm{faz}$ com que o autor proponha de forma diacrônica uma oposição entre luz e sombra separando "um momento aglutinador" de "um momento rarefeito", essa oposição poderia também ser produtiva se trabalhada sincronicamente, percebendo o contexto amplo do cinema brasileiro de uma forma mais nuançada, explorando sua diversidade na representação daquele momento da sociedade e da cultura.

Uma percepção de estruturas/projetos permitiria reavaliar aspectos centrais do período, dando maior inteligibilidade a conjuntos de filmes, como o cinema extraordinário da Difilm em sua diferença do cinema da Embrafilme, o político e o econômico repercutindo sobre o estético e o estilístico, ou a produção regional de filmes de realizadores ligados à Associação Brasileira de Documentarista. Da mesma forma como a percepção das repercussões do ajuste de uma cultura transformadora numa cultura de mercado sob o mecenato direto ou indireto estatal traz elementos 80 que "Idade da Terra", embora tendo a textura de um filme udigrudi, é produzido com prioridade pelo Estado, permite enfrentar impasses na compreensão dessa continuidade do cinema épico de Glauber, personagem crucial de um pacto faustiano a que, menos adaptativo, não resiste.

Assim, paralelamente ao cinema cultural e depois institucionalmente hegemônico no início desses mesmos anos 70, era fundada a Associação Brasileira dos Documentaristas, em 1971, como representação política das novas gerações pós-64 no novo contexto cinematográfico que havia se redefinido com o surgimento da Embrafilme em 1969. É sobre o universo desses realizadores ligados à $\mathrm{ABD}$ no Rio de Janeiro e a cooperativa cinematográfica Corcina, e seus filmes, que dedico o final dessa comunicação.

Assim, procuro voltar meu foco para um universo menos visitado pelos especialistas, menos visível portanto para a sociedade, de filmes de uma geração de cineastas culturalmente mais diversificados e politicamente afastados do poder, que surgem na virada daqueles anos 70 reunidos em torno de pequenas produtoras, coletivos e cooperativas. Como setor geracional específico, falamos de homens e mulheres nascidos entre a segunda metade dos anos 40 e a segunda metade dos 50 , que aparecem e tr ansitam, assistem, discutem, fazem e mostram cinema nos ambientes do Festival JB, da Cinemateca do Museu da Arte Moderna, na Associação 
Brasileira de Documentaristas, muitos convergindo anos mais tarde para cooperativa de realizadores, a CORCINA.

Resumindo uma primeira visão desse grupo e antecipando uma abordagem teórico-metodológica: um cinema libertário onde se escutam os ecos das esquerdas como da contracultura (política); realizado através da coletivização irregular e eventualmente paradoxal de recursos e esforços mobilizados por organizações coletivas e utilizados por diretoresprodutores (economia); apostando na superação lúdica das restrições do cinema corrente através de linguagens artísticas e propostas cinematográficas experimentais e evolutivas (estética), se referindo às transformações como as reavaliações da tradições da sociedade carioca/ brasileira na representação daqueles anos de chumbo (História).

Me parece compreensível porque o ambiente cinematográfico teria naquele momento uma "leitura difícil" para aqueles novos participantes que herdam propostas estéticas e políticas das vanguardas nacionais já no contexto dos governos militares. A transformação dos antigos revolucionários sub-reptícia e depois ostensivamente na nova elite e a ambigüidade do seu discurso como a dá própria ação estatal "enfrentando" o inimigo comum, o cinema norte-americano, desestruturam uma oposição política e frentes alternativas de produção, estimulando posturas cada vez mais anárquicas, disseminando a descrença mesmo na participação mesmo dos órgãos de classe, o que garantiu o controle dos órgãos de classe pelo notáveis e a renovação das "frentes-únicas". No entanto. se a insuficiência de uma proposta de mercado que superasse a rejeição do mercado na mão das multinacionais e do Estado protagonista terminaria por atomizar os grupos e afastar muitos dos seus participantes da atividade. isto não impediu a floração de uma safra importante de filmes, tanto quantitativa como qualitativamente. Farta de curtas e magra de longa-metragens, diria que esse setor da produção carioca corresponde à realização - e, hoje, a um acervo potencial - de 300 à 400 curtas e de 30 a 40 longas -, documentários e ficcionais, cuja produção se estendeu subalternamente. frente ao mercado, à mídia e à história, do final dos anos 70 até o final dos 80 .

Filmes que partem de características estilísticas, temáticas e culturais geracionalmente comuns a esse universo de tecno-artistas reunidos na cidade do Rio de Janeiro, mas onde as diversidades entre os realizadores vão se acentuando, frente ao progressivo realizado através da coletivização irregular e eventualmente paradoxal de recursos e esforços mobilizados por organizações coletivas e utilizados por diretores-produtores (economia); apostando na superação lúdica das restrições do cinema corrente através de linguagens artísticas e propostas cinematográfićas experimentais e evolutivas (estética), se referindo às transformaçōes como as reavaliações da tradições da sociedade carioca/brasileira na representação daqueles anos de chumbo (História). 
Me parece compreensível porque o ambiente cinematográfico teria naquele momento uma "leitura difícil" para aqueles novos participantes que herdam propostas estéticas e políticas das vanguardas nacionais já no contexto dos governos militares. A transformação dos antigos revolucionários sub-reptícia e depois ostensivamente na nova elite e a ambigüidade do seu discurso como a da própria ação estatal "enfrentando" o inimigo comum, o cinema norte-americano, desestruturam uma oposição política $:$ frentes alternativas de produção, estimulando posturas cada vez mais anárquicas, disseminando a descrença mesmo na participação mesmo dos órgãos de classe, o que garantiu o controle dos órgãos de classe pelo notáveis e a renovação das "frentes-únicas". No entanto, se a insuficiência de uma proposta de mercado que superasse a rejeição do mercado na mão das multinacionais e do Estado protagonista terminaria por atomizar os grupos e afastar muitos dos seus participantes da atividade, isto não impediu a floração de uma safra importante de filmes, tanto quantitativa como qualitativamente. Farta de curtas e magra de longa-metragens, diria que esse setor da produção carioca corresponde à realização - e, hoje, a um acervo potencial - de 300 à 400 curtas e de 30 a 40 longas -, documentários e ficcionais, cuja produção se estendeu subalternamente, frente ao mercado, à mídia e à história, do final dos anos 70 até o final dos 80 .

Filmes que partem de características estilísticas, temáticas e culturais geracionalmente comuns a esse universo de tecno-artistas reunidos na 82 cidade do Rio de Janeiro, mas onde as diversidades entre os realizadores vão se acentuando, frente ao progressivo amadurecimento de alguns com o metier, como à irregularidade no trabalho e na vida impostas pela crise permanente, e pela progressiva fragmentação dos grupos. Procuro então me voltar para os filmes produzidos, oferecer ao leitor uma relação dos seus títulos, detalhar suas tramas e seus temas, discutir suas teses, abordar sua textura cinematográfica. Mas sou detido pela falta absoluta de informações organizadas. O que existe na bibliografia do período, considerando os livros publicados e as revistas especializadas editadas, é a "história sagrada" onde esse universo é apenas aflorado. Procuro então discutir idéias matriciais e fazer algumas generalizações.

Um primeiro aspecto organiza essas idéias: o golpe militar e o ultrarealismo que isso provoca no universo cultural brasileiro termina (episodicamente) o episódio dos "movimentos político-culturais" - tanto o cinema de certezas do Cinema Novo como o cinema de dúvidas do Udigrude não tem mais vez, embora permaneçam atuantes seus personagens.

Naqueles anos 70 tanto as organizações políticas como os coletivos de realização seriam, não mais "movimentos", mas "movimentações", no sentido de participação coletivizada em atividades onde os parâmetros 
ideológicos e estéticos eram mais abertos, permitindo uma extrema diversificação - existencial, política, social - entre seus participantes. Isso imediatamente quer dizer que falamos de uma filmografia que tem aspectos bastante diversificados.

No entanto, algumas discussões eram centrais nessa movimentaçĩo de jovens realizadores, como a do caráter ilusionista da linguagem do cinema ficcional e a busca de respostas a isso, questão plantada pelos "movimentos" do Cinema Novo e radicalizada pelo Udigrude e ainda profundamente influente, como referência dos recém-chegados. Assim. essa inquietação frente às linguagens estabelecidas é um aspecto central, que se mantém do momento anterior naquele novo, marcado pela heterogenia dos participantes a diversidade das respostas. $O$ que entretanto caracteriza essa geração e essa filmografia precisa é uma exiensão dessa discussão, quando a questão do ilusionismo da linguagem se estende para uma segunda órbita do ilusionismo localizada no cinema documentário.

Os procedimentos do documentário são alternativas imediatas frente à limitação dos recursos e a urgência dessa nova geração de realizadores, técnicos e artistas em testemunhar cinematograficamente aqueles anos de chumbo e marcam a textura desses filmes, mesmo os explicitamente ficcionais. O conceito de cinema documentário também teria que se renovar para abordar aqueles em que esse aspecto parece dominante. apesar de desestabilizado por efeitos paródicos, de desconstrução. ou da inclusão de recursos da linguagem ficcional. O esmaecimento das fronteiras entre ficção e documentário, como um aspecto central nas representaçōes desses outros olhos daquela sociedade brasileira. Filmes realizados fora da indústria, de forma individual ou cooperativada. improvisados e experimentais. estetizantes e obsessivos.

Poder-se-ia estabelecer um paralelo entre o New American Cinema no período conhecido como underground, uma recusa ao cinema roliudiano. e esse cinema brasileiro paralelo, alternativo, dos anos 70 e 80 , embora não saiba de relaçōes entre cineastas brasileiros e norte-americanos. Assim, como no New Cinema são produzidos no Brasil filmes autorais. militantes, poéticos e formalistas, não mais vinculados a um mesmó programa mas de diversas orientações estéticas e ideológicas, representando uma rebelião contra aspectos do cinema dominante que pareciam ilegítimos: o retorno ao sistema clássico e a uma orientação política populista do quisto rebelde e a ausência de opções no conservadorismo explicito no "cinema comercial". a traição das esquerdas, o narcisismo midiático. o controle tas "concorrências".

Como no New American Cinema, muitos dos realizadores tiveram uma aproximação tanto artesanal como conceitual. muitos trazendo conhecimentos e experiência de outros campos técnicos e artísticos, alguns 
acompanhando seus filmes com uma produção teórica importante, entrando em dissonância com os fóruns organizados pelos sindicatos dos grandes produtores ou pelopróprio Estado onde as discussões se despolitizam de propostas estético-culturais se voltando exclusivamente para questões da chamada "política cinematográfica".

Os anos 70 seriam anos de crescimento desse setor do cinema brasileirs, . que informado e politizado por sua participação na $\mathrm{ABD}$, nos fóruns informáuis desse cinema alternativo e nas seções dos cineclubes, uma vez que o mercado do longa já se encontrava saturado pelo filme norteamericano e pelo filme estatal - opta pelo mercado que se abre para o curtametragem, definido como complemento obrigatório em qualquer programa com longa-metragem estrangeiro na mesma lei que cria a Embrafilme em 69. A apresentação dos filmes em festivais amadores e depois profissionais de curta-metragem, a criação da $\mathrm{ABD}$ e a luta até a regulamentação da lei, conduziriam o setor a seu momento de maior produtividade, quando esta entra em vigor, o que acontece no final da década/ início dos anos 80 , quando é fundada no Rio por 45 realizadores a CORCINA - Cooperativa dos Realizadores Cinematográficos Autônomos.

A própria Embrafilme cria na sua distribuidora um setor de curtametragem, mas a oposição do cinema americano com sua política de mandatos de seguranças, seu lobby no congresso brasileiro e suas ameaças aos produtores nacionais de longa-metragem ligados ao órgão estatal, e a 84 própria "burla legal" - quando os exibidores criam produtoras-fantasma para "cumprir a lei -, tornariam os 80 instáveis e depressivos. Entretanto nesses anos são produzidos filmes particularmente expressivos desse universo, muitos dos realizadores desenvolvendo projetos ousados e experimentais de longa-metragens.

No momento, desenvolvo um trabalho de pesquisa no Departamento de Cinema e Vídeo da UFF com um grupo de alunos-pesquisadores de graduação que tem como objetivo de abordar o fenômeno do cinema alternativo - um acontecimento nacional - no Rio de Janeiro, disponibilizando esses filmes e as idéias que os sustentaram para a história e para a sociedade brasileira. Assim, trabalhamos para montar uma base de dados, a ser divulgada tanto na internet, como através de um catálogo e de $\mathrm{CD}$-Rom, apresentando esse universo cinematográfico carioca, verbeteando seus filmes, e trazendo entrevistas, artigos - daquele momento e de agora desses realizadores e de críticos e pesquisadores sobre os acontecimentos, seus personagens $\epsilon$ sobre as obras. Um dos aspectos principais que justificam esse esforço é trazer para a contemporaneidade do cinema e da sociedade brasileira as propostas da produção independente e de formas coletivistas de realização cinematográfica que caracterizaram o "cinema alternativo", que me parecem fundamentais nesse momento em que a 
comunicação de massa e a produção cultural são controladas pelo capital internacional e por grandes redes nacionais e multinacionais de entretenimento e informação

Se produzimos uma história-problema, polêmica em virtude de seus aspectos apenas indiciares e conjecturais, se esta história não é jamais inocente, se sua imparcialidade é vulnerável a subjetividades, ideologias e topismos, se abrimos mão de qualquer pretensão em produzir um discurso de verdade - sabemos que podemos constatar a veracidade dos fenômenos históricos e sobre eles produzir, num esforço coletivo nos questionando e realimentando, análises e conclusões argumentáveis, conhecimento que tomado na medida do homem consequentemente se humaniza, ganhando rigor na percepção de seus limites e de suas possibilidades. nos conferindo o peso de identidades comuns próprias e possibilidades de conhecimento para dialetizar com a imediaticidade dos acontecimentos, luz para nos mantermos no caminho na escolha do próximo passo.

\section{Notas:}

'«J'ai voulu dégager une certaine philosophie des événements, des œuvres, des faits, tâchant de situer l'évolution artistique. industrielle et économique du film dans son contexte social universel e de justifier ses structures en justifiant de son infrastructure. En bref, je me suis efforcé de faire de l'histoire au sens exact du mot.», " Histoire du cinéma », Édition Universitaires, Paris, 1967.

${ }^{2}$ «Un vaste panorama impressionniste, avec des points de lumière et des zones d'ombre. que ne structure aucune ligne de force.». « Un bilan navré des histoires du cinéma françaises, ou L histoire du cinéma rançais: pour une approche immédiatement opératoire ", in : « Histoire du Cinéma, Nouvelles approches», Publications de la Sorbonne, 1989.

${ }^{4}$ Instituto Nacional do Livro.

${ }^{5}$ ROCHA, Glauber, "Revolução no Cinema Novo", Ed. Alhambra \& Embrafilme, RJ, 1981.

${ }^{6}$ Ed. Civilização Brasileira, RJ.

${ }^{7}$ ROCHA, Glauber,

${ }^{8}$ Art Editora, SP. 


\title{
Bibliografia
}

CARVALHO SOARES, Mariza de \& FERREIRA, Jorge (orgs.). "A História vai ao Cinema", Record, RJ, 2001.

MITRY, Jean. «"Histoire du cinéma ", Édition Universitaires, Paris, 1967. MOURA, Roberto. « Cinema brasileiro : atualidades e reminiscências inspiradoras » in: Cinemais, $n^{\circ} 10$, março/ahril 98.

"A história sagrada do cinema brasileiro e o cinema invisível",

Cinemais, ${ }^{\circ} 17$, maio/junho 99.

RAMOS, Fernão (org.). "História do Cinema Brasileiro", Art Ed., SP 87.

RAMOS, Fernão \& MIRANDA, Luiz Felipe (orgs.). "Enciclopédia do

Cinema Brasileiro", SENAC, SP, 2000.

ROCHA, Glauber. "Revisão crítica do cinema brasileiro", Civilização

Brasileira, RJ, 63.

SALLES GOMES, Paulo Emílio. "Humberto Mauro, Cataguases, Cinearte", Perspectiva, SP, 74.

"Cinema: trajetória no subdesenvolvimento", Paz e Terra, SP, 80.

VIANY, Alex. "Introdução ao Cinema Brasileiro", Alhambra, RJ, 87.

XAVIER, Ismail. "O cinema brasileiro moderno", Paz e Terra, SP, 2001.

\author{
Palavras chave \\ história do cinema brasileiro \\ modernidade \\ contemporaneidade \\ cooptação \\ modernidade conservadora
}

